\title{
Effect of Flue Gas Components on the Adsorption of Sulfur Oxides on $\mathrm{CaO}$ (100)
}

Benjamin Galloway, Bihter Padak*

*Corresponding author

Department of Chemical Engineering, University of South Carolina, Columbia, South Carolina

29201

\begin{abstract}
Due to the prevalence of coal combustion technologies utilizing calcium-based materials, it is important to understand the varied reactions between the flue gas species and these calciumbased materials. Of particular importance is the reaction between sulfur oxides $\left(\mathrm{SO}_{2}\right.$ or $\left.\mathrm{SO}_{3}\right)$ and calcium oxide $(\mathrm{CaO})$, which plays an important role in sulfur retention on fly ash during oxycoal combustion or carbon capture with calcium looping. To better understand these reactions, density functional theory (DFT) calculations were performed investigating $\mathrm{SO}_{\mathrm{x}}$ binding to $\mathrm{CaO}$ surfaces functionalized by other flue gas components. Analyses of the energetic, geometric and electronic nature of the modeled systems were conducted. Generally, the most stable conformation on the surface is in the form of either a sulfite- or sulfate-like structure. Water can have an effect on sulfur binding by introducing other favorable intermediate conformations, while carbon dioxide could negatively impact adsorption by weakening sulfur-surface bonds.
\end{abstract}

Key Word: Sulfur, Calcium oxide, DFT, oxy-combustion 


\section{Introduction}

Coal-fired power plants account for nearly $33 \%$ of the electricity generated in the U.S. in 2015 [1]. Due to the varied and complex composition of coal, many harmful and regulated pollutants are emitted during the combustion reaction. One of the pollutants of great concern is sulfur, which can comprise $0.5-5 \%$ of the coal [2]. Despite the varied forms that sulfur can take in coal, such as organic, pyritic $\left(\mathrm{FeS}_{2}\right)$ or sulfatic, it is generally emitted in the form of sulfur oxides $\left(\mathrm{SO}_{2}\right.$ or $\left.\mathrm{SO}_{3}\right)$ with power plants being responsible for emitting over 3 million tons in 2012 $[2,3]$. In order to meet current regulations covering $\mathrm{SO}_{\mathrm{x}}$, over $60 \%$ of power plants utilize flue gas desulfurization (FGD) scrubbers [3]. These scrubbers capture the gaseous sulfur species through the interaction with a calcium-based sorbent, commonly limestone $\left(\mathrm{CaCO}_{3}\right)$ [4]. Not all sulfur released during the combustion of coal is captured in these units, as part of it is mitigated due to retention on fly ash particles of which Ca can constitute up to $40 \%$ [5-8]. In fact, fly ash with greater weight fractions of $\mathrm{Ca}$ or other alkali and alkaline earth metal oxides yields reduced $\mathrm{SO}_{\mathrm{x}}$ emissions through greater sulfur retention [9-16]. It is this beneficial impact of the fly ash that has attempts to capture and re-purpose spent fly ash as a cost effective sorbent for sulfur emissions $[17,18]$.

More recently, Ca-based materials have faced new challenges as the focus for coal-fired power plants has shifted to reducing $\mathrm{CO}_{2}$ emissions. One proposed solution for lowering $\mathrm{CO}_{2}$ emission is oxy-fuel combustion. Oxy-combustion, where nitrogen $\left(\mathrm{N}_{2}\right)$ is separated prior to combustion to create a concentrated $\mathrm{CO}_{2}$ stream after condensation of water, experiences increased sulfur retention on fly ash when compared to air combustion [9]. This increased capture has been attributed to the increased formation of $\mathrm{SO}_{3}$ detected under oxy-fuel conditions, i.e. higher $\mathrm{SO}_{\mathrm{x}}$ concentration and greater $\mathrm{SO}_{3}: \mathrm{SO}_{2}$ ratio $[19,20]$. Calcium-looping is another 
proposed technology for limiting $\mathrm{CO}_{2}$ emissions that relies very heavily on Ca-based materials $[21,22]$. In Ca-looping, calcium oxide $(\mathrm{CaO})$ is cycled through carbonation $\left(\mathrm{CaO}\right.$ to $\left.\mathrm{CaCO}_{3}\right)$ and calcination $\left(\mathrm{CaCO}_{3}\right.$ to $\left.\mathrm{CaO}\right)$ reactors to produce pure $\mathrm{CO}_{2}$. While other technologies can rely on the $\mathrm{Ca}-\mathrm{S}$ interaction to mitigate sulfur emissions, in $\mathrm{Ca}$-looping this interaction can be problematic. As $\mathrm{Ca}-\mathrm{S}$ products are more stable than $\mathrm{CaCO}_{3}$, exposure of the $\mathrm{Ca}$-sorbent to sulfur containing flue gas can cause permanent deactivation, requiring replacement of the sorbent over time.

Given the predominant nature of combustion systems relying on $\mathrm{Ca}-\mathrm{S}$ interactions mentioned here, increasing the understanding of such reactions can aid in limiting sulfur emissions. Additionally, this study was conducted in conjunction with our experimental work on $\mathrm{CaO}$ for oxy-coal combustion application (which can be found here [23] ). The objective of this work is to analyze the effect that the various flue gas species $\left(\mathrm{H}_{2} \mathrm{O}, \mathrm{CO}_{2}, \mathrm{SO}_{2}\right.$ and $\left.\mathrm{SO}_{3}\right)$ have on the binding of $\mathrm{SOx}\left(\mathrm{SO}_{2}\right.$ or $\left.\mathrm{SO}_{3}\right)$ to $\mathrm{CaO}$ through the use of density functional theory (DFT) calculations. Simulation results reveal information regarding the changing structure and binding energy of the sulfur compounds as they interact with a clean surface, as well as ones with previously adsorbed flue gas species. Additional analyses involving the density-of-states and charge distribution of the final systems were performed to further examine the effect that the changing environment would have on the electronic interaction between the sulfur species and the surface. Finally, ab-initio thermodynamic calculations were conducted to investigate the effect of temperature on the binding of single adsorbates.

\section{Computational Methodology}

To examine the binding of combustion products to calcium oxide, a $\mathrm{CaO}(100)$ surface was simulated. To do this, DFT calculations were performed using a plane wave basis set with 
Vienna ab-initio simulation package (VASP) [24-28]. The key computational parameters with respect to energetic and electronic optimization calculations are summarized here with more detail mentioned in our previous publication [29]. The generalized gradient approximation method of Perdew and Wang was employed for projector augmented wave potentials [30-33]. The energy of the plane waves was capped at $520 \mathrm{eV}$ with energy and force convergence criteria set to $10^{-5} \mathrm{eV}$ and $0.03 \mathrm{eV} / \AA$ respectively. Energetic optimization calculations were conducted using Monkhorst-Pack mesh of $3 \times 3 \times 1$ with electronic ones for density-of-states (DOS) analyses using a $11 \times 11 \times 1$ scheme. The parameters used result in good agreement with experimental geometries for the $\mathrm{CaO}$ surface and various gas phase species as summarized in Table 1. Analyses into the electronic structure were conducted through the investigation of the optimized systems' density-of-states (information for this is again outlined in our previous work [29]). Calculations involving charge transfer occurring during the reactions were conducted using the Bader method using the script developed by Henckleman et al. [34-37]. Finally, ab-initio thermodynamic calculations were conducted for the single-adsorbate systems. The relevant equations and methodology for this will be discussed later in the corresponding section.

In order to model the multi-adsorbate (MA) systems, single-adsorbate (SA) systems were first modeled. Initial calculations examined the adsorption of a single adsorbate, either $\mathrm{H}_{2} \mathrm{O}, \mathrm{CO}_{2}$ $\mathrm{SO}_{2}$ or $\mathrm{SO}_{3}$, onto the $\mathrm{CaO}$ (100) surface at a $1 / 8 \mathrm{ML}$ coverage. The binding energy was calculated using Eq. 1a. For systems where multiple adsorbates were present, Eq. 1b was used to calculate the binding energy of the second adsorbate molecule using the energy from the singleadsorbate system. The results for single-adsorbate calculations were required as a baseline for the analysis of multi-adsorbate systems and agree well with previously reported binding energies for $\mathrm{H}_{2} \mathrm{O}, \mathrm{CO}_{2}, \mathrm{SO}_{2}$ and $\mathrm{SO}_{3}[29,38-41]$ 


$$
\begin{array}{lll}
\Delta E_{\text {Binding }}=-\left(E_{\text {Final SA System }}-E_{\text {Clean Slab }}-E_{\text {Gas Phase Species }}\right) & \text { Eq.1a } \\
\Delta E_{\text {Binding }}=-\left(E_{\text {Final MA System }}-E_{\text {SA Slab }}-E_{\text {Gas Phase Species }}\right) & \text { Eq. } 1 \mathrm{~b}
\end{array}
$$

As the results for single adsorbate-surface interactions on $\mathrm{CaO}$ have already been reported, they will only be discussed here briefly as a basis for comparison for the multiadsorbate systems. The multi-adsorbate systems were modeled by first allowing one of the species to fully relax and optimize on the surface. This includes the $-\mathrm{H},-\mathrm{OH},-\mathrm{CO}_{2},-\mathrm{SO}_{2}$ and $\mathrm{SO}_{3}$ surfaces mentioned earlier. In addition to the $-\mathrm{H}$ and $-\mathrm{OH}$ systems, a $-\mathrm{H} \& \mathrm{OH}$ surface, where both $-\mathrm{H}$ and $-\mathrm{OH}$ functional exist, was also investigated for sulfur adsorption. The inclusion of both was based on previous research in conjunction with a desire to expand upon the $-\mathrm{H}$ or $-\mathrm{OH}$ results presented here [40-43]. In these cases, the $-\mathrm{OH}$ and $-\mathrm{H}$ were assumed to dissociate and slightly separate with the $-\mathrm{OH}$ moving to the next nearest neighbor. While not as energetically favored as $\mathrm{H}_{2} \mathrm{O}$ adsorption, the dissociation reaction was still predicted to have a positive binding energy, again in agreement with previous studies [43]. The distinctions between the $-\mathrm{H}$ or $-\mathrm{OH}$ and the $-\mathrm{H} \& \mathrm{OH}$ surfaces will be discussed in greater detail later. After convergence of a single adsorbate, a second adsorbate, $\mathrm{SO}_{2}$ or $\mathrm{SO}_{3}$, was then brought near the surface over several binding sites nearest to the original adsorbate in multiple orientations. In this way, the complex surface reactions that take place under actual flue gas conditions can be better understood. In all cases, numerous starting geometries were modeled and only the results and analyses of the most stable configurations were reported here.

\section{Results}

\subsection{Surface Binding of $\mathrm{SO}_{2}$}


The results presented here and previous research have shown $\mathrm{SO}_{2}$ and $\mathrm{SO}_{3}$ to be binding to $\mathrm{CaO}$ in a sulfite- or sulfate-like structure, respectively $[29,38,39]$. These monodentate structures were calculated to be the most stable on the (100) surface. Figure 1(i) shows $\mathrm{SO}_{2}$ adsorbing in the sulfite-like structure on a clean surface. The images in Figure 1(ii-vi) illustrate how the same structure results mostly regardless of the pre-adsorbed molecule, $-\mathrm{OH},-\mathrm{H} \&-\mathrm{OH}$, $-\mathrm{CO}_{2},-\mathrm{SO}_{2}$ or $-\mathrm{SO}_{3}$. (The results from the $-\mathrm{H}$ surface predict $\mathrm{SO}_{2}$ interacting in a nonmonodentate sulfite-like structure making strict one-to-one comparisons to the results presented here unreasonable. This and a similar interaction between the $-\mathrm{H}$ surface and $\mathrm{SO}_{3}$ will be discussed later in the "Interaction with $\mathrm{H}_{2} \mathrm{O}$ " section.) Table 2 summarizes the calculated results for a variety of energetic, geometric, and electronic parameters.

Using Equation 1(a-b), the binding energy of $\mathrm{SO}_{2}$ can be compared for various functionalized surfaces. As it is seen from Table 2, the clean surface exhibits the greatest binding energy (BE). The BE gradually decreases in the following order: $-\mathrm{H} \& \mathrm{OH}>$ clean $>-$ $\mathrm{OH}>-\mathrm{SO}_{2}>-\mathrm{CO}_{2}>-\mathrm{SO}_{3}$. What stands out among these results is that the $-\mathrm{H} \& \mathrm{OH}$ systems have a $\mathrm{BE}$ greater than the clean surface while the $\mathrm{BE}$ for the others steadily decreases relative to the clean surface. Despite the changes in BE, it causes relatively minor changes in the bond distances between sulfur and oxygen from the gas-phase $\mathrm{SO}_{2}$ molecule $\left(\mathrm{S}-\mathrm{O}_{\mathrm{SO}}\right)$, the average angle between sulfur and oxygens in the newly formed sulfite-structure $\left(\mathrm{O}_{\mathrm{SO} 2}-\mathrm{S}-\mathrm{O}_{\mathrm{SO} 2}\right)$ and the distance between sulfur and lattice oxygen $\left(\mathrm{S}-\mathrm{O}_{\text {Lat }}\right)$. These values change less than $0.05 \AA, 7.0^{\circ}$, and $0.1 \AA$, respectively. The greatest change is evident in the $\mathrm{SO}_{3}$-adsorbed surface resulting in a longer $\mathrm{S}-\mathrm{O}_{\mathrm{Lat}}$ bond distance, as the $\mathrm{BE}$ decreases $44 \%$ from 180 to $101 \mathrm{~kJ} / \mathrm{mol}$. The $\mathrm{S}-\mathrm{O}_{\mathrm{SO} 2}$ bond distance remains relatively similar and $\mathrm{O}_{\mathrm{SO} 2}-\mathrm{S}-\mathrm{O}_{\mathrm{SO} 2}$ bond angle increases compared to that of the clean structure possibly due to the sterics of the larger $\mathrm{SO}_{3}$ molecule on the surface. 
Table 2 further describes the electronic structure of the systems and how the binding and charge distribution in the systems change. These results were obtained from the DOS calculations using more rigorous k-point scheme to ensure electronic accuracy. Shifts in orbital energy were calculated from examining the lowest energy s-orbital for the atom being investigated. A negative value indicates that the orbital shifted to a lower energy (downward shift). Conversely, shift to a higher energy (upward shift) is represented by a positive value. The shift in these orbitals can be a reasonable metric of the resulting bond between the adsorbate and the surface. The specific atoms listed in Table 2 include the sulfur atom from the adsorbing $\mathrm{SO}_{2}$ and the previously bonded surface species referred to as the other adsorbate. This would include the $\mathrm{O}$ in the $\mathrm{OH}$ group from the $-\mathrm{OH}$ surface, $\mathrm{C}$ from the $-\mathrm{CO}_{2}$ surface, and $\mathrm{S}$ from the $-\mathrm{SO}_{2}$ or $\mathrm{SO}_{3}$ surfaces. For the $-\mathrm{H} \& \mathrm{OH}$ systems two values are given with the first being for the $\mathrm{H}$ bonded to the surface and the second being the $\mathrm{O}$ in the $\mathrm{OH}$ group. This way the shifts can be compared to their $-\mathrm{H}$ or $-\mathrm{OH}$ counterparts. This value is not applicable for the clean surface as there is no pre-adsorbed species. The DOS plot for the $-\mathrm{OH}$ surface is presented in Figure 2 as an example showing the $\mathrm{S}$ in $\mathrm{SO}_{2}$ and $\mathrm{O}$ in the $\mathrm{OH}$ group before and after binding. The DOS plots for the remaining systems are included in Figure S.1 in the Supplementary Materials. As previously mentioned, the Bader method was employed to perform the charge transfer analysis, which calculates the total charge change for the adsorbing $\mathrm{SO}_{2}$ molecule from the initial gasphase species. For these results, negative values indicate an increase in electron density or population causing an increase in negative charge on the atom. Additionally, the values listed in Table 2 were calculated from the difference in the total charge before and after binding for all of the relevant atoms in the $\mathrm{SO}_{2}$ molecule. 
Examining the results yields several trends regarding binding of $\mathrm{SO}_{2}$ on functionalized surfaces. Similar to the interaction with the clean surface, the sulfur s-orbital shifts downward due to the stability of the sulfite species on the surface. The differences in the shifts for the $-\mathrm{OH}$, $-\mathrm{CO}_{2}$ and $-\mathrm{SO}_{2}$ functional surfaces are relatively minor mirroring the small change in $\mathrm{BE}$. While the $-\mathrm{SO}_{3}$ surface results in a noticeably smaller shift resulting in the smaller binding energy, the $\mathrm{H} \& \mathrm{OH}$ surface experiences the greatest downward shift indicative of its larger BE. These shifts are representative of the hybridization of the sulfur orbitals with the lattice oxygen. Additionally, the s-orbital of the previously adsorbed species is simultaneously shifted up. The upward shift shows how the binding of a second adsorbate weakens the binding of the first (preadsorbed) molecule. For the $-\mathrm{H} \& \mathrm{OH}$ systems, this upward shift is observed for both atoms being investigated.

The charge transfer values presented in Table 2 are the calculated difference between the charge distribution for the clean surface or gas-phase molecule and their counterparts in the final structure for either single- or multi-adsorbate systems. From the data, it is clear that the functionalized surfaces do exhibit some effect on the adsorbing $\mathrm{SO}_{2}$ molecule. On the clean surface, the $\mathrm{SO}_{2}$ molecule becomes electron deficient, relative to the gas-phase, with most of the charge being lost by the $\mathrm{S}$ going to the binding lattice oxygen. However, if the surface has a previously adsorbed species, the $\mathrm{SO}_{2}$ molecule observes only minimal change where the charge transfer to the $\mathrm{SO}_{2}$ is relatively small.

\subsection{Surface Binding of $\mathrm{SO}_{3}$}

Similar to the way $\mathrm{SO}_{2}$ forms a monodentate sulfite structure, the most energetically favorable surface structure of $\mathrm{SO}_{3}$ is a monodentate sulfate species, which forms on all surfaces 
as shown in Figure 3(i-vii). A summary of the $\mathrm{SO}_{3}$ binding results is shown in Table 3. The BE for $\mathrm{SO}_{3}$ on these surfaces also follows a similar trend as $\mathrm{SO}_{2}$, i.e., $-\mathrm{H} \& \mathrm{OH}>$ clean $>-\mathrm{OH}>-$ $\mathrm{SO}_{2}>-\mathrm{CO}_{2}>-\mathrm{SO}_{3}>-\mathrm{H}$. Again $\mathrm{OH}, \mathrm{SO}_{2}$ and $\mathrm{CO}_{2}$ are the least detrimental to binding, while $\mathrm{SO}_{3}$ inhibits binding the most and $-\mathrm{H} \& \mathrm{OH}$ is slightly beneficial. However, unlike the $\mathrm{SO}_{2}, \mathrm{SO}_{3}$ is predicted to bind to the $-\mathrm{H}$ surface in a monodentate sulfate structure leading to its inclusion here. Similar to the $-\mathrm{SO}_{3}$ surface, the $-\mathrm{H}$ surface exhibits a large decrease in $\mathrm{BE}$ relative to the clean one. Variations in the $\mathrm{BE}$ yield minimal geometric changes as observed for the $\mathrm{SO}_{2}$ binding case. The inherent stability of the sulfate prevents significant changes in geometry from surface to surface as $\mathrm{S}-\mathrm{O}_{\mathrm{SO} 3}$ bond distance, $\mathrm{O}_{\mathrm{SO} 3}-\mathrm{S}-\mathrm{O}_{\mathrm{SO} 3}$ bond angle and $\mathrm{S}-\mathrm{O}_{\mathrm{Lat}}$ bond distance experience changes of less than $0.01 \AA, 1.0^{\circ}$ and $0.05 \AA$, respectively.

The electronic properties for the $\mathrm{SO}_{3}$ systems mostly follow the same trends as the BE. The DOS plots generated for the analysis are included in Figure S.2 in the Supplementary Materials. The downward shifts in the S s-orbital increase as the binding energies increase, while the previously adsorbed species experience an upward shift in their s-orbital. (As with the $\mathrm{SO}_{2}$ systems, the other adsorbates for the $\mathrm{SO}_{3}$ systems mentioned in Table 3 correspond to $\mathrm{H}$ from the $-\mathrm{H}$ surface, $\mathrm{O}$ in the $\mathrm{OH}$ group from the $-\mathrm{OH}$ surface, $\mathrm{H}$ bonded to the surface and $\mathrm{O}$ in the $\mathrm{OH}$ group, respectively in the $-\mathrm{H} \& \mathrm{OH}$ surface, $\mathrm{C}$ from the $-\mathrm{CO}_{2}$ surface, and $\mathrm{S}$ from the $\mathrm{SO}_{2}$ or $-\mathrm{SO}_{3}$ surfaces.) The exception is the $-\mathrm{H}$ surface, which, despite the largest decrease in $\mathrm{BE}$, experiences the largest downward shift of over $5 \mathrm{eV}$. Additionally, the $\mathrm{H}$ in the $-\mathrm{H}$ surface experiences a significant downward shift in its s-orbital while all other adsorbed species experiences a relatively minimal upward shift. Finally, the Bader analysis reveals minimal charge change on the $\mathrm{SO}_{3}$ either for the clean or functionalized surfaces. The difference from the 
$\mathrm{SO}_{2}$ case is likely due to the greater coordination of the sulfur in $\mathrm{SO}_{3}$, which prevents it from donating charge as $\mathrm{SO}_{2}$ does, even on a clean surface.

\subsection{Surface Interactions with $\mathrm{H}_{2} \mathrm{O}$}

Some of the systems have a predicted final configuration wherein the binding sulfur is not interacting with the surface lattice oxygen. The resulting geometric configurations for these systems are shown in Figure 4(i-viii) while the key geometric and electronic properties are summarized in Table 4. These systems with water functionals are characterized by the electronic interaction between the gas-phase $\mathrm{SO}_{\mathrm{x}}$ species and the surface functional groups, specifically the $-\mathrm{OH}$ and $-\mathrm{H}$.

Figure 4(i-iv) shows the formation of bisulfite/bisulfate-like structures $\left(\mathrm{HSO}_{\mathrm{x}}\right)$ from the interaction of $\mathrm{SO}_{2} / \mathrm{SO}_{3}$ with the $-\mathrm{OH}$ on either the $-\mathrm{OH}$ (i-ii) or $-\mathrm{H} \& \mathrm{OH}$ (iii-iv) surfaces. The $\mathrm{BE}$ associated with the formation of these bisulfite/bisulfate species is less on the $-\mathrm{OH}$ surface, but greater on the $-\mathrm{H} \& \mathrm{OH}$ surface when compared to adsorption of $\mathrm{SO}_{\mathrm{x}}$ species onto a clean surface. The S-O $\mathrm{O}_{\mathrm{SOx}}$ bond distances are elongated while the $\mathrm{O}_{\mathrm{SOx}}-\mathrm{S}-\mathrm{O}_{\mathrm{SOx}}$ bond angles are decreased, similar to those for surface bound sulfite/sulfate groups. The $\mathrm{S}-\mathrm{O}_{\mathrm{OH}}$ bond distance is greater than the normal S- $\mathrm{O}_{\mathrm{SOx}}$ bond distances due to the presence of the $\mathrm{H}$ atom creating a hydroxyl group. The overall bisulfate structure is in agreement with bisulfate ions in water reported in a previous computational study by Vchirawongkwin et al. [44]. The S-O $\mathrm{O}_{\text {Lat }}$ distance is also greatly increased compared to the previously discussed results as the orientation of the $\mathrm{HSO}_{\mathrm{x}}$ structures in Figure 4(i-iv) show the $\mathrm{O}$ atoms in the $\mathrm{HSO}_{\mathrm{x}}$ preventing the sulfur from binding to the surface. 
The $\mathrm{HSO}_{\mathrm{x}}$ orientation, coupled with greater distance to the surface, leads to an essentially non-existent surface interaction, confirmed through analyses of the DOS plots shown in Figure 5(i-iv) with additional DOS plots included in Figure S.3 in the Supplementary Materials. Figures 5(i\&iii) display how the sulfur s- and p-orbitals exhibit no overlap with the underlying lattice oxygen although an overlap was observed for all of the sulfite/sulfate structures. Despite no overlap, a downward shift is still observed. Additionally, Figures 5(ii\&iv) show how the formation of the $\mathrm{HSO}_{\mathrm{x}}$ species weakens the $-\mathrm{OH}$ group's bond with the surface by analyzing the $\mathrm{Ca}$ atoms around the hollow site and the $-\mathrm{OH}$ before and after optimization. Investigation of these DOS plots provides evidence that despite the energetic favorability of $\mathrm{HSO}_{\mathrm{x}}$ formation, the $\mathrm{HSO}_{\mathrm{x}}$ species do not interact strongly with the surface the way the $\mathrm{SO}_{\mathrm{x}}$ species shown in Figures 1 and 3 do.

Despite the similarities observed in the formation of bisulfite/bisulfate on the $-\mathrm{OH}$ and $\mathrm{H} \& \mathrm{OH}$ surfaces, further electronic analysis yields several notable differences. The first is the Ss orbital shifts, with larger downward shifts associated with the higher BE on the $-\mathrm{H} \& \mathrm{OH}$ surface. This is re-iterated in the $\mathrm{O}_{\mathrm{OH}}$ shift, which differs by -0.8 and -0.85 for bisulfite and bisulfate, respectively from the $-\mathrm{OH}$ and the $-\mathrm{H} \& \mathrm{OH}$ systems. The Bader analysis shows how both the bisulfite and bisulfate systems go through significant charge change relative to $\mathrm{SO}_{\mathrm{x}}$ adsorption onto the various functionalized surfaces. On the $-\mathrm{OH}$ surface, the charge transfer to the sulfur molecule is significant at -0.25 and -1.06 for $\mathrm{SO}_{2}$ and $\mathrm{SO}_{3}$, respectively, which confirms the bisulfate formation as the bisulfate ion holds a -1 charge.

The second type of weak surface interaction occurs on the $-\mathrm{H}$ surface, where an $\mathrm{O}$ atom from the $\mathrm{SO}_{\mathrm{x}}$ molecule interacts with the $\mathrm{H}$ resulting in a $\mathrm{H}+\mathrm{SO}_{\mathrm{x}}$ configuration as shown in Figure 4(v-viii). Relative to the clean surface, this configuration is energetically more favorable 
for $\mathrm{SO}_{2}$ and slightly less favorable for $\mathrm{SO}_{3}$. Similar to the bisulfite/bisulfate systems, the sulfur atom in the $-\mathrm{H}$ systems does not interact or bond to the surface. Additionally, the configuration cannot be described to be fully forming a hydroxyl group, as the H-O SOx bond $(1.82$ and $1.92 \AA$ for $\mathrm{SO}_{2}$ and $\mathrm{SO}_{3}$, respectively) is much longer than $\sim 1 \AA$, which is the calculated distance for the other O-H bonds.

Similar to the bisulfite/bisulfate structures, the final $\mathrm{H}+\mathrm{SO}_{\mathrm{x}}$ systems for this weak interaction on the $-\mathrm{H}$ and $-\mathrm{H} \& \mathrm{OH}$ surfaces differ with respect to their electronic structure. The sulfur s-orbital in $\mathrm{SO}_{2}$ for $-\mathrm{H}$ containing systems experiences a larger downward shift in agreement with the slight increase in $\mathrm{BE}$ relative to $\mathrm{SO}_{2}$ binding to a clean surface. This is in contrast to the sulfur s-orbital in $\mathrm{SO}_{3}$ for $-\mathrm{H}$ containing systems, which experiences a slight upward shift relative to the clean surface. Again, similar to the bisulfite/bisulfate structures, the $-\mathrm{H}+\mathrm{SO}_{\mathrm{x}}$ systems experience a large charge transfer to the initial gas-phase $\mathrm{SO}_{\mathrm{x}}$ molecule with the $-\mathrm{H}$ only system experiencing a slightly larger charge transfer. The large charge transfer primarily comes at the expense of the lattice oxygen, which initially goes through a charge increase after binding to the $\mathrm{H}$ atom. The transfer away from the lattice oxygen due to the interaction with the $\mathrm{SO}_{\mathrm{x}}$ species also seems to explain the upward shift observed in $\mathrm{O}_{\mathrm{Lat}} \mathrm{S}$-orbital.

Most of the weak surface interactions only occur with respect to functionalized surfaces that could be found if water is present (i.e. the $-\mathrm{H},-\mathrm{OH}$, and $-\mathrm{H} \& \mathrm{OH}$ surfaces). For the $-\mathrm{H}$ and $-\mathrm{OH}$ surfaces, the model in this work assumes $\mathrm{H}_{2} \mathrm{O}$ dissociates and that the functional groups have migrated far enough away to examine each functional group's individual impact on the binding of $\mathrm{SO}_{\mathrm{x}}$ species. This dissociation reaction of $\mathrm{H}_{2} \mathrm{O}$ on $\mathrm{CaO}$ surface has been modeled by other groups in the literature and has generally been found to be energetically favorable, but becomes less so as the $-\mathrm{OH}$ and $-\mathrm{H}$ species move farther and farther apart $[40,41,43]$. One of 
the reasons presented is that the two functional groups aid in charge stabilizing each other. Taking this conclusion into account provides valuable insight to the reason why the $\mathrm{H}_{2} \mathrm{O}$ functionalized surfaces behave the way they do. All of the weak-surface-interaction cases are characterized by large charge transfer relative to the clean surface. This might explain why many of the systems have the highest BE of any of the functionalized surfaces. The presence of $\mathrm{SO}_{\mathrm{x}}$ helps to stabilize the surface where only one of the functional groups is present. The large charge transfer might also explain why the $\mathrm{SO}_{2}$ does not form the sulfite structure on the $-\mathrm{H}$ surface. The weaker $\mathrm{S}-\mathrm{O}_{\mathrm{Lat}}$ interaction of $\mathrm{SO}_{2}$ compared to $\mathrm{SO}_{3}$ seems to not be able to overcome the charge effect, which seems to prevent it from forming a surface bond. The more strongly reacting $\mathrm{SO}_{3}$ can bond to the surface, but at a significantly decreased binding energy.

\subsection{Sulfur-Sulfur Interactions}

Other than sulfite/sulfate and bisulfite/bisulfate species, many other sulfur oxides, specifically di-sulfur compounds, are known to form experimentally [45, 46]. However, after analyzing the DOS plots for the previously discussed systems, the initial results do not converge to any configuration with a substantial sulfur-sulfur interaction. The most likely explanation being that to form the $\mathrm{S}-\mathrm{S}$ bond, the $\mathrm{S}-\mathrm{O}_{\text {lat }}$ bond must first be broken, which was not predicted in any of the calculations performed. Since the methodology for these calculations is based on examining the effect of pre-adsorbed or functionalized surfaces, the methodology was amended to determine if any such interactions are possible on the $\mathrm{CaO}$ surface. In order to examine the potential S-S interactions, both sulfur species were allowed to converge simultaneously, as opposed to sequentially as it had previously been done. 
Figure 6(i-iii) shows the most energetically favorable conformation for the calculations involving the modified methodology with Table 5 summarizing key parameters. The figures show the formation of a dithionite $\left(\mathrm{S}_{2} \mathrm{O}_{4}\right)$, disulfite $\left(\mathrm{S}_{2} \mathrm{O}_{5}\right)$, dithionate $\left(\mathrm{S}_{2} \mathrm{O}_{6}\right)$ from the reaction of $\mathrm{SO}_{2}+\mathrm{SO}_{2}, \mathrm{SO}_{2}+\mathrm{SO}_{3}$ and $\mathrm{SO}_{3}+\mathrm{SO}_{3}$ respectively. Analyses of the geometries for these configurations provide further evidence of the formation of these disulfur oxyanions. Values and trends with respect to bond distances and bond angles are in good agreement when compared to previous gas phase simulations by McKee and experimental crystal structure analysis by Carter et al. and Magnusson et al. [47-49]. Some of the discrepancies between the results previously reported and those presented here might be related to the charge difference, as the model here is based on two neutral gas phase molecules coming together whereas the previous work focused on ionic solids or gases. However, examining the calculated Bader charge change indicates that the molecules do experience substantial charge transfer similar to the other weak surface $\mathrm{HSO}_{\mathrm{x}}$ species. The species shown in Figure 6 (i\&iii) experience increasing charge transfer with the $\mathrm{S}_{2} \mathrm{O}_{6}$ having a -2 charge after convergence, in agreement with its expected charge in an ionic $\mathrm{S}_{2} \mathrm{O}_{6}$ species. The exception to this is the $\mathrm{S}_{2} \mathrm{O}_{5}$, where the less coordinated sulfur in $\mathrm{SO}_{2}$ is bound to the surface mitigating the charge change similar to other sulfite or sulfate species.

Much like the bisulfite/bisulfate systems interacting with the $-\mathrm{OH}$ and $-\mathrm{H} \& \mathrm{OH}$ surfaces, the newly formed sulfur compounds do not exhibit any significant interaction with the surface. The $\mathrm{S}_{2} \mathrm{O}_{4}$ and $\mathrm{S}_{2} \mathrm{O}_{6}$ systems are in an O-down orientation limiting the $\mathrm{S}-\mathrm{O}_{\text {Lat }}$ binding, and, while not shown in the figure, a similar configuration is predicted for $\mathrm{S}_{2} \mathrm{O}_{5}$. These systems are characterized by their minimal interaction with the surface, confirmed through the DOS analysis, as well as the low BE. The calculated $\mathrm{BE}$ for the $\mathrm{S}_{2} \mathrm{O}_{4}, \mathrm{~S}_{2} \mathrm{O}_{5}$, and $\mathrm{S}_{2} \mathrm{O}_{6}$ systems are 46,80 , and $140 \mathrm{~kJ} / \mathrm{mol}$, respectively. (The $\mathrm{S}_{2} \mathrm{O}_{5}$ system with this $\mathrm{BE}$ is not shown in Figure 6) One 
exception is the $\mathrm{S}_{2} \mathrm{O}_{5}$ system shown in Figure 6(ii), which has a much larger BE of $246 \mathrm{~kJ} / \mathrm{mol}$. The $\sim 160 \mathrm{~kJ} / \mathrm{mol}$ difference between the two $\mathrm{S}_{2} \mathrm{O}_{5}$ systems is due to the presence of the surface lattice oxygen bond to the less coordinated $\mathrm{SO}_{2}$ sulfur and is approximately equal to the $\mathrm{BE}$ of $\mathrm{SO}_{2}$ to a clean or functionalized surface. Despite the low $\mathrm{BE}$, the sulfur atoms in the disulfur ions do experience some downward shift in the sulfur s-orbital, albeit much less in the $\mathrm{S}_{2} \mathrm{O}_{6}$ species compared to the others as shown in Figure S.4 in the Supplementary Materials and summarized in Table 5. For the case of $\mathrm{S}_{2} \mathrm{O}_{5}$, the first value provided in Table 5 is the shift for the $\mathrm{SO}_{2}$ binding to the $\mathrm{O}_{\text {Lat }}$ and the second value is the gas-phase $\mathrm{SO}_{3}$ forming the $\mathrm{S}-\mathrm{S}$ bond. For the surface $\mathrm{SO}_{2}$, this shift is greater than the one observed for $\mathrm{SO}_{2}$ binding to the functionalized surfaces, but as the sulfur in this configuration is forming multiple bonds (with $\mathrm{O}_{\text {Lat }}$ and $\mathrm{S}$ ) it is difficult to compare them directly. Furthermore, as calculated for other systems, the surface bond in the $\mathrm{S}_{2} \mathrm{O}_{5}$ system limits charge transfer to the resulting di-sulfur compound as opposed to the $\mathrm{S}_{2} \mathrm{O}_{4}$ and $\mathrm{S}_{2} \mathrm{O}_{6}$ systems.

\subsection{Ab-initio Thermodynamic Calculations}

In an attempt to relate the idealized conditions of the DFT results to those obtained experimentally, additional calculations were conducted to calculate the free energies from the binding energies already presented. The equations employed here are based on those previously reported whose methodologies are widely followed in the literature $[50,51]$. The binding energies previously presented from using Equation 1 are expanded upon to obtain the free energy of reaction at various temperatures and reaction conditions. For these calculations, only the single-adsorbate systems were investigated. To calculate the change in the Gibbs free energy $(\Delta \mathrm{G})$, Eq. 2a was used. For the calculation of the free energy the negative sign, included in Eq. 
1 , is excluded to maintain the conventional reference for $\Delta \mathrm{G}$ to see if it is greater or less than zero.

$$
\begin{gathered}
\Delta G=\Delta E_{D F T}+\Delta F_{v i b}-\sum_{i} N_{i} \mu_{i} \\
F_{v i b}=\sum_{i} \frac{\hbar \omega_{i}}{2}+k_{b} T \ln \left(1-\exp \left(-\frac{\hbar \omega_{i}}{k_{b} T}\right)\right. \\
\mu_{i}(T, p)=\mu_{i}\left(T, p^{o}\right)+k_{b} T \ln \left(p_{i} / p_{o}\right)
\end{gathered}
$$

The $\Delta \mathrm{E}_{\mathrm{DFT}}$ is the calculated binding energy using Equation 1 and values for which are presented in the previous sections. As DFT calculation are done under static conditions, the $\Delta \mathrm{F}_{\text {vib }}$ adds the energy associated with vibrational motion, according to Equation $2 b$ with the first term in Eq $2 b$ representing the zero-point energy $\left(\mathrm{E}_{\mathrm{ZPE}}\right)$. The equation requires the estimation of the vibrational frequencies $\left(\omega_{\mathrm{i}}\right)$, which, similar to DOS calculations, are conducted on a previously converged system. As a correction, calculated vibrational modes below $100 \mathrm{~cm}^{-1}$ are set to $100 \mathrm{~cm}^{-1}$ to ensure greater accuracy when applying the harmonic approximation in Eq. 2 as previous researchers have also done $[52,53]$. Finally, Equation $2 \mathrm{c}$ adds in the pressure and temperature affects to the pure components' chemical potentials $\left(\mu_{\mathrm{i}}\right)$. (As no phase change is investigated, the chemical potential contribution is assumed to come only from the gas-phase species.) The first term in Eq. $2 \mathrm{~d}$ is calculated using the NIST-JANAF tables according to the procedure outlined by Cleary [54, 55]. The pressure correction was done for two different gas compositions, air and oxy-combustion flue gases. Due to the lack of nitrogen in the oxy-combustion system and the introduction of a recycle stream, the concentration of all species generally increases from air to oxy combustion. The compositions employed in the calculations here are presented in Table 5. 
Figure 7 shows the estimated change in free energy for the single-adsorbate systems from ambient to high temperatures (300-1200K) under air and oxy-combustion environments. While $\mathrm{H}_{2} \mathrm{O}$ is always the least and $\mathrm{SO}_{3}$ is the most favorable, $\mathrm{CO}_{2}$ adsorption becomes more favorable than $\mathrm{SO}_{2}$ at intermediate temperatures. The specific temperature where the trend is changing is different depending on the environment. The free energy curves of $\mathrm{CO}_{2}$ and $\mathrm{SO}_{2}$ cross at $\sim 725 \mathrm{~K}$ for air combustion and $\sim 675 \mathrm{~K}$ for oxy-combustion as a result of the higher $\mathrm{CO}_{2}$ and $\mathrm{SO}_{2}$ concentrations in the gas-phase for oxy-combustion.

\section{Discussion}

The results presented here describe the variety of sulfur interactions that can occur on a $\mathrm{CaO}$ surface and provide insight into describing some of the experimental results reported in the literature. Firstly, for any given system, $\mathrm{SO}_{3}$ binds more strongly than $\mathrm{SO}_{2}$. This agrees with previous literature, which found a similar trend when investigating $\mathrm{SO}_{2}$ and $\mathrm{SO}_{3}$ binding to various other alkali or alkaline earth metal oxides [29, 38, 39]. This trend does not change with respect to the various surface functional groups investigated here. Secondly, the geometries for these systems tend to mimic a sulfite- or sulfate-like structure. Finally, most of the functionalized surfaces inhibit sulfur binding. While the geometry experiences little change, the BE decreases reflecting the weaker S-O $\mathrm{Lat}_{\text {at }}$ bond as also seen by smaller S-s orbital shifts in the DOS plots.

The negative impact of $\mathrm{CO}_{2}$ is of particular interest due to the high concentration $\mathrm{CO}_{2}$ atmosphere in oxy-combustion. The results from the oxy-combustion experiments in our earlier publication confirm the negative impact of $\mathrm{CO}_{2}$ up to $850^{\circ} \mathrm{C}$, above which $\mathrm{CO}_{2}$ can no longer inhibit sulfur adsorption [23]. This is evident in Figure 7 where $\mathrm{CO}_{2}$ adsorption becomes more favorable than $\mathrm{SO}_{2}$ at a lower temperature under an oxy-combustion environment compared to 
air-combustion environment. Although, the impact can be slightly obscured as the experimental results attributed the inhibition of sulfur binding to the formation of $\mathrm{CaCO}_{3}$, potentially changing the reaction mechanism as the surface changes. Alternatively, as the binding of $\mathrm{SO}_{3}$ is always the most thermodynamically favorable, the main driver behind sulfur capture could be the $\mathrm{SO}_{3}$ species despite its low concentration. This could explain why greater sulfur retention was observed experimentally on oxy-combustion fly ash as greater $\mathrm{SO}_{3}$ concentrations are expected in oxy-combustion environments $[9,19,20]$.

While most multi-adsorbate systems are expected to negatively impact $\mathrm{SO}_{\mathrm{x}}$ binding, water is predicted to enhance sulfur binding to the surface in multiple ways. Firstly, the presence of $-\mathrm{H} \& \mathrm{OH}$ was the only configuration to increase the binding energy of $\mathrm{SO}_{2}$ and $\mathrm{SO}_{3}$ where all other pre-adsorbed species $\left(\mathrm{CO}_{2}\right.$ and $\left.\mathrm{SO}_{\mathrm{x}}\right)$ caused a decrease in binding energy. In addition to the decrease in $\mathrm{BE}$, bond strength between the sulfur atom and the surface is weakened as calculated from the smaller shifts in the S-s orbitals from the DOS analyses. The enhancement of the $\mathrm{BE}$ can aid in understanding the results collected from the exposure of Ca-based materials to water containing flue gas streams from numerous experimental studies. Two in-situ surface studies by Baltrusaitis et al. and $\mathrm{Al}$ Hosney et al. reported the importance of $\mathrm{H}_{2} \mathrm{O}$ on the formation of sulfur products, particularly sulfite ones, on $\mathrm{CaCO}_{3}[56,57]$. Two separate studies conducted by Zhao et al. show a trend of increasing sulfation of limestone $\left(\mathrm{CaCO}_{3}\right)$ with increasing water partial pressure $[58,59]$. Additional studies on limestone state that $\mathrm{CaO}$ is an intermediate in the indirect sulfation of $\mathrm{CaCO}_{3}$ [58-62]. So despite $\mathrm{CaCO}_{3}$ being the starting material, the results here can help explain the beneficial effect of $\mathrm{H}_{2} \mathrm{O}$ on sulfation in regimes where the indirect sulfation reaction dominates. While not directly investigated here, the positive effect of $\mathrm{H}_{2} \mathrm{O}$ on sulfur binding might explain the beneficial effects of $\mathrm{H}_{2} \mathrm{O}$ on $\mathrm{CO}_{2}$ 
reactions observed experimentally by Wang et al. and Galloway et al. [23, 63]. However, the impact of $\mathrm{H}_{2} \mathrm{O}$ on the binding of sulfur cannot be solely responsible for the effect on reactivity, as studies by $\mathrm{Li}$ et al. ascribe the increase in carbonation to bulk phenomena, such as pore structure changes caused by the carbonation reaction [64]. It should also be noted that, the unfavorable thermodynamics for water adsorption on $\mathrm{CaO}(100)$, as shown in Figure 7, suggest that water is the least likely to bind to the surface among all the adsorbates considered.

While the presence of $\mathrm{H}_{2} \mathrm{O}$ is calculated to increase the surface BE, it also facilitated additional surface reactions beyond forming simple sulfite/sulfate structures. Surfaces with an $\mathrm{OH}$ group were predicted to form bisulfite or bisulfate from $\mathrm{SO}_{2}$ or $\mathrm{SO}_{3}$ binding, respectively. Bisulfite and bisulfate species are likely intermediates to sulfite or sulfate products. This may explain why other studies investigating $\mathrm{SO}_{2}$ adsorption to $\mathrm{CaCO}_{3}$ do not observe bisulfate [56, 57]. These species are likely short-lived intermediates to the sulfate or sulfite structures, especially at higher operating temperatures representing combustion applications. Along with the possible intermediates formed through the interaction with the $\mathrm{OH}$ groups, the $\mathrm{H}$ group also facilitated an interaction that could be thought of as an intermediate to the final sulfite or sulfate structure. The $-\mathrm{H}$ only surface is an exception where the charge transfer to the binding $\mathrm{SO}_{2}$ molecule seems to prevent its binding to the lattice oxygen as $\mathrm{SO}_{3}$ is able to do. As with bisulfite/bisulfate, the formation of various di-sulfur compounds predicted here are likely shortlived, with minimal experimental evidence suggesting that they form $[56,57,65]$. Where the bisulfite/bisulfate forms a strong S-O bond, the S-S bond is relatively weak. This, coupled with the minimal surface interaction, makes it probable that these species are stabilized on the surface and would decompose further away from the surface as gas-phase species. Finally, the methodology was amended from sequential to simultaneous adsorption of the gas-phase species. 
This effectively turns a 2-body reaction to a 3-body one, making it inherently far less likely that these di-sulfur species would form. The exception to this is the $\mathrm{S}_{2} \mathrm{O}_{5}$ configuration, which does form a surface bond. However, similar to the intermediate species associated with $\mathrm{H}_{2} \mathrm{O}$, this could be short-lived before transitioning to a sulfate and sulfite by breaking the relatively weak S-S bond.

\section{Conclusion}

The interactions occurring between $\mathrm{SO}_{2}$ or $\mathrm{SO}_{3}$ on functionalized $\mathrm{CaO}(100)$ surfaces were predicted from DFT calculations. Trends in binding energy along with orbital shifts from DOS analyses show the negative impact, relative to a clean surface, most pre-adsorbed species ($\mathrm{CO}_{2},-\mathrm{SO}_{2},-\mathrm{SO}_{3},-\mathrm{OH}$, and $\left.-\mathrm{H}\right)$ have on both $\mathrm{SO}_{2}$ and $\mathrm{SO}_{3}$ in forming surface sulfite or sulfate species, respectively. $\mathrm{CO}_{2}$ is of particular interest as further thermodynamic calculations on the single-adsorbate surfaces reveal how $\mathrm{CO}_{2}$ could potentially inhibit sulfur capture as $\mathrm{CO}_{2}$ binding becomes more favorable than $\mathrm{SO}_{2}$ at higher temperatures, possibly making $\mathrm{SO}_{3}$ the only active species for sulfur binding. While the negative impact of pre-adsorbed species is observed in most systems, hydrated $(-\mathrm{H} \& \mathrm{OH})$ surfaces aid adsorption by increasing the binding energy and surface bond strength relative to the clean surface. Additionally, hydroxylated surfaces $(-\mathrm{OH}$ and $-\mathrm{H} \& \mathrm{OH}$ ) are predicted to form bisulfite or bisulfate-like structures, that are energetically favorable while not bonded to the surface. However, minimal experimental evidence of these species suggests that they are short-lived intermediates before converting to the more stable sulfate-like structure. Secondary interactions with the $\mathrm{H}$ in $-\mathrm{H}$ and $-\mathrm{H} \& \mathrm{OH}$ systems could likewise act as intermediates to surface sulfite or sulfate species. Finally, while di-sulfur compounds are predicted to form, they exhibit marginal surface interaction and may not significantly affect sulfur adsorption. 


\section{Acknowledgements}

The authors would like to acknowledge the Extreme Science and Engineering Discovery Environment (XSEDE) and Texas Advanced Computing Center (TACC) at The University of Texas at Austin for providing HPC resources that have contributed to the research results reported within this paper. This work was supported by the National Science Foundation under award number 1236761 and an undergraduate student who helped this project was funded by the Research Experiences for Undergraduates (REU) Program of the National Science Foundation under award number 1358931. The authors acknowledge the help of Alexandra Bland and Angel Maymi Rolon in running some of the DFT calculations and Dr. Andreas Heyden for his guidance in conducting the ab-initio thermodynamic calculations. 


\begin{tabular}{|c|c|c|c|c|c|}
\hline & $\mathbf{C a O}^{[\mathbf{a}]}$ & $\mathbf{S O}_{2}^{[\mathbf{b}]}$ & $\mathbf{S O}_{\mathbf{3}}{ }^{[\mathbf{b}]}$ & $\mathbf{C O}_{\mathbf{2}}{ }^{[\mathbf{b}]}$ & $\mathbf{H}_{\mathbf{2}} \mathbf{O}^{[\mathbf{b}]}$ \\
\hline Calc. & 4.814 & 1.447 & 1.435 & 1.176 & 0.971 \\
\hline Exp. & 4.839 & 1.431 & 1.42 & 1.160 & 0.958 \\
\hline
\end{tabular}

Table 1. Calculated and experimental values for lattice and bond lengths.

${ }^{\mathrm{a}}$ Reference [66]

${ }^{\mathrm{b}}$ Reference [67] 
(i)

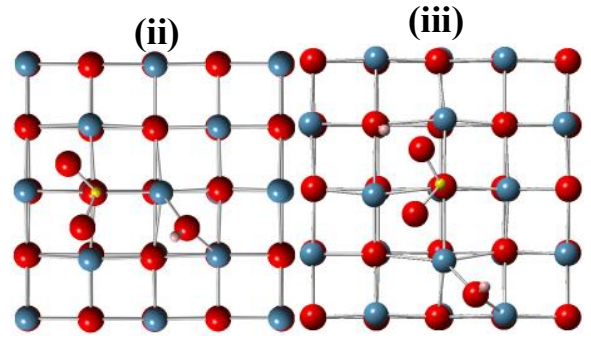

(iv)

(v)

(vi)

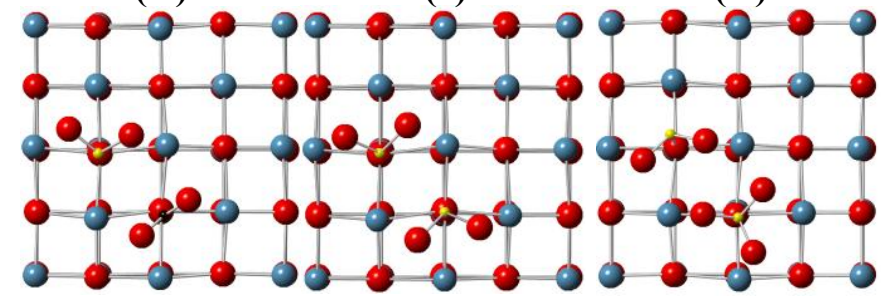

Figure 1. $\mathrm{SO}_{2}$ binding in a sulfite-like structure to $\mathrm{CaO}(100)$ surface that is clean (i) or has a preadsorbed $-\mathrm{OH}$ (ii), $-\mathrm{H} \& \mathrm{OH}(\mathrm{iii}),-\mathrm{CO}_{2}$ (iv), $-\mathrm{SO}_{2}$ (v) or $-\mathrm{SO}_{3}$ (vi). 


\begin{tabular}{|c|c|c|c|c|c|c|}
\hline Surface Functional & Clean & $-\mathrm{OH}$ & $-\mathrm{H \& OH}$ & $-\mathrm{CO}_{2}$ & $-\mathrm{SO}_{2}$ & $-\mathrm{SO}_{3}$ \\
\hline Binding Energy & 180 & 171 & 215 & 145 & 157 & 101 \\
\hline $\begin{array}{l}\text { S-O OSO2 Bond } \\
\text { Distance }(\AA)\end{array}$ & 1.462 & 1.505 & 1.516 & 1.503 & 1.506 & 1.491 \\
\hline $\begin{array}{c}\mathrm{O}_{\mathrm{SO} 2-\mathrm{S}-\mathrm{O}_{\mathrm{SO} 2} \text { Bond }} \text { Angle }\left({ }^{\circ}\right) \\
\text { And }\end{array}$ & 115.6 & 110.8 & 108.9 & 109.4 & 109.5 & 115.4 \\
\hline S-O Lat $_{\text {Distance }(\AA)}$ & 1.704 & 1.699 & 1.665 & 1.704 & 1.712 & 1.747 \\
\hline $\begin{array}{c}\text { Shift in S-s orbital } \\
(\mathrm{eV})\end{array}$ & -1.28 & -1.13 & -1.85 & -1.18 & -1.15 & -0.89 \\
\hline $\begin{array}{c}\text { Shift in Other } \\
\text { Adsorbate-s orbital } \\
(\mathrm{eV})\end{array}$ & -- & 0.07 & $0.63 / 0.09$ & 0.56 & 0.12 & 0.29 \\
\hline $\begin{array}{c}\text { Total Charge } \\
\text { Transfer to } \mathrm{SO}_{2}\end{array}$ & +0.983 & -0.050 & -0.019 & -0.052 & -0.053 & -0.108 \\
\hline
\end{tabular}

Table 2. Summary of results for $\mathrm{SO}_{2}$ binding on $\mathrm{CaO}$ surfaces with various adsorbates shown in Figure 1. The columns (from top to bottom) list the calculated binding energy, S-O bond distance within the original $\mathrm{SO}_{2}$ molecule, the O-S-O bond angle within the original $\mathrm{SO}_{2}$ molecule, the bond distance from the $\mathrm{S}$ to the lattice $\mathrm{O}$, shift in $\mathrm{S}$ s-orbital, shift in s-orbital of pre-adsorbed species, and the total charge transfer to the $\mathrm{SO}_{2}$ after binding. The shift in the other adsorbate corresponds to the $\mathrm{O}$ in the $\mathrm{OH}$ group from the $-\mathrm{OH}$ surface, $\mathrm{C}$ from the $-\mathrm{CO}_{2}$ surface, and $\mathrm{S}$ from the pre-adsorbed $-\mathrm{SO}_{2}$ or $-\mathrm{SO}_{3}$ surfaces. For $-\mathrm{H} \& \mathrm{OH}$ surface, the first number is the shift in the $\mathrm{H}$ bonded to the lattice $\mathrm{O}$ and the second is the shift of the $\mathrm{O}$ in the $\mathrm{OH}$ group. 


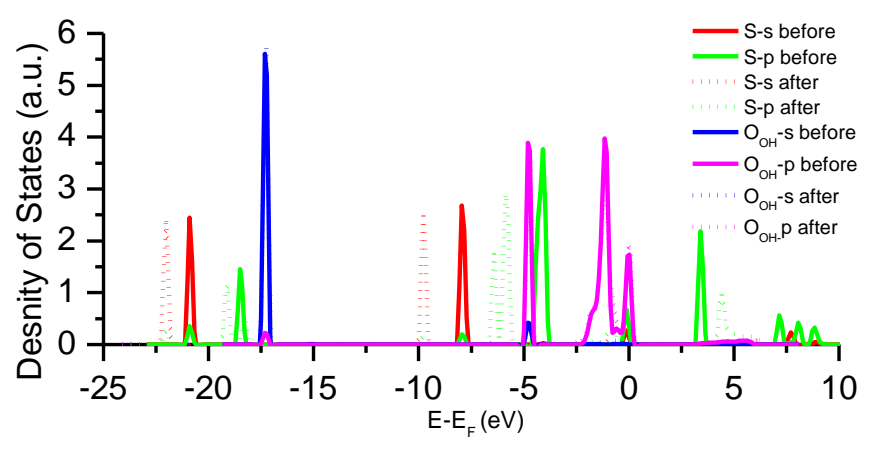

Figure 2. Density of states plot for $\mathrm{SO}_{2}$ binding to the $-\mathrm{OH}$ surface showing the s\&p-orbitals of the $\mathrm{S}$ atom and $\mathrm{O}$ atom in $\mathrm{OH}$ before and after binding. 
(i)

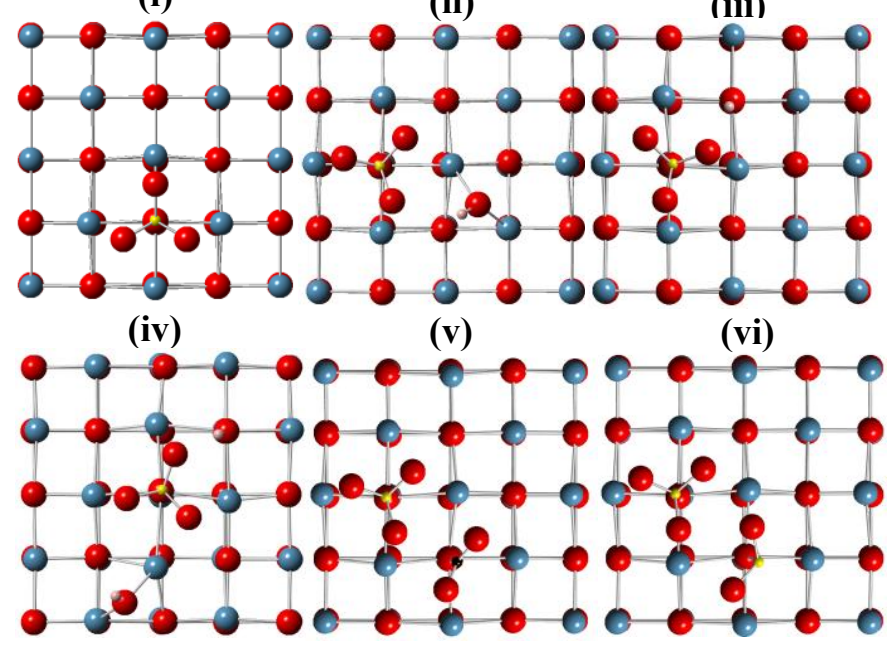

(vii)

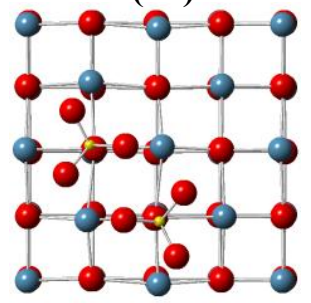

Figure 3. $\mathrm{SO}_{3}$ binding in a sulfate-like structure to $\mathrm{CaO}(100)$ surface that is clean (i) or has a pre-adsorbed $-\mathrm{OH}$ (ii), $-\mathrm{H}$ (iii), $-\mathrm{H} \& \mathrm{OH}$ (iv), $-\mathrm{CO}_{2}$ (v), $-\mathrm{SO}_{2}$ (vi), $-\mathrm{SO}_{3}$ (vii). 


\begin{tabular}{|c|c|c|c|c|c|c|c|}
\hline $\begin{array}{l}\text { Surface } \\
\text { Functional } \\
\text { Group }\end{array}$ & Clean & $-H$ & $-\mathrm{OH}$ & -H\&OH & $-\mathrm{CO}_{2}$ & $-\mathrm{SO}_{2}$ & $-\mathrm{SO}_{3}$ \\
\hline $\begin{array}{c}\text { Binding Energy } \\
(\mathbf{k J} / \mathbf{m o l})\end{array}$ & 319 & 233 & 312 & 353 & 276 & 279 & 234 \\
\hline $\begin{array}{l}\text { S-O } \mathrm{S}_{\mathrm{So} 3} \text { Bond } \\
\text { Distance }(\AA)\end{array}$ & 1.470 & 1.474 & 1.471 & 1.475 & 1.469 & 1.469 & 1.467 \\
\hline $\begin{array}{c}\text { O}_{\mathrm{SO3}_{3}-\mathrm{S}-\mathrm{O}_{\mathrm{SO3} 3}} \\
\text { Bond Angle }\left({ }^{\circ}\right)\end{array}$ & 113.9 & 113.7 & 113.8 & 113.4 & 113.9 & 113.9 & 114.1 \\
\hline $\begin{array}{c}\text { S-O } \\
\text { Lat Distance } \\
\text { (§) }\end{array}$ & 1.622 & 1.610 & 1.615 & 1.591 & 1.620 & 1.619 & 1.634 \\
\hline $\begin{array}{l}\text { Shift in S-s } \\
\text { orbital (eV) }\end{array}$ & -1.5 & -5.09 & -1.4 & -2.01 & -1.43 & -1.42 & -1.29 \\
\hline $\begin{array}{l}\text { Shift in Other } \\
\text { Adsorbate-s } \\
\text { orbital }(e V)\end{array}$ & --- & -1.98 & 0.16 & $0.54 / 0.12$ & 0.56 & 0.53 & 0.22 \\
\hline $\begin{array}{c}\text { Total Charge } \\
\text { Transfer to } \mathrm{SO}_{3}\end{array}$ & -0.046 & -0.085 & -0.062 & -0.065 & -0.048 & -0.034 & -0.032 \\
\hline
\end{tabular}

Table 3. Summary of results for $\mathrm{SO}_{3}$ binding on $\mathrm{CaO}$ surfaces with various adsorbates shown in Figure 2. 
(i)

(ii)
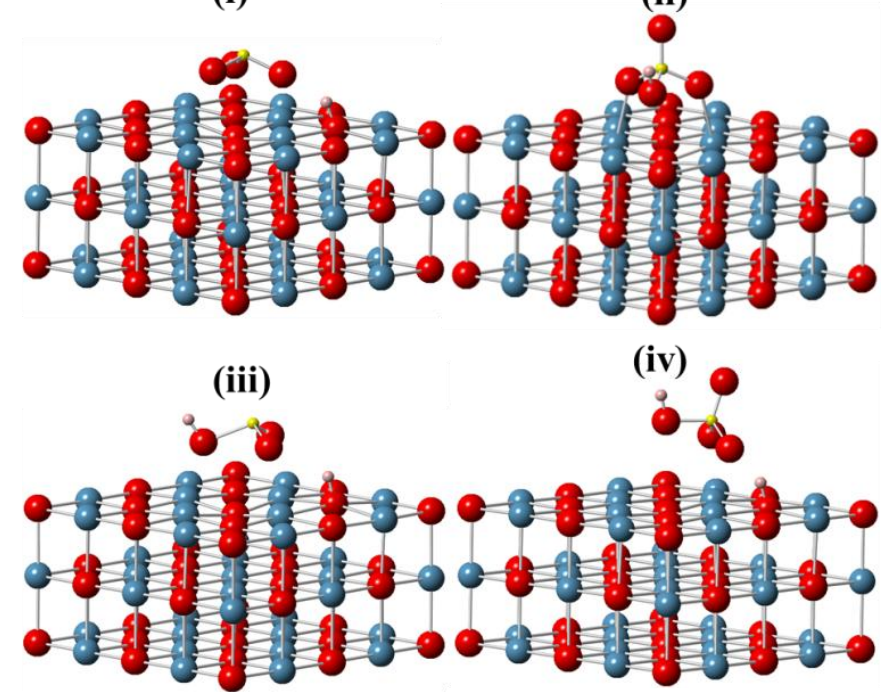

(v)

(vi)

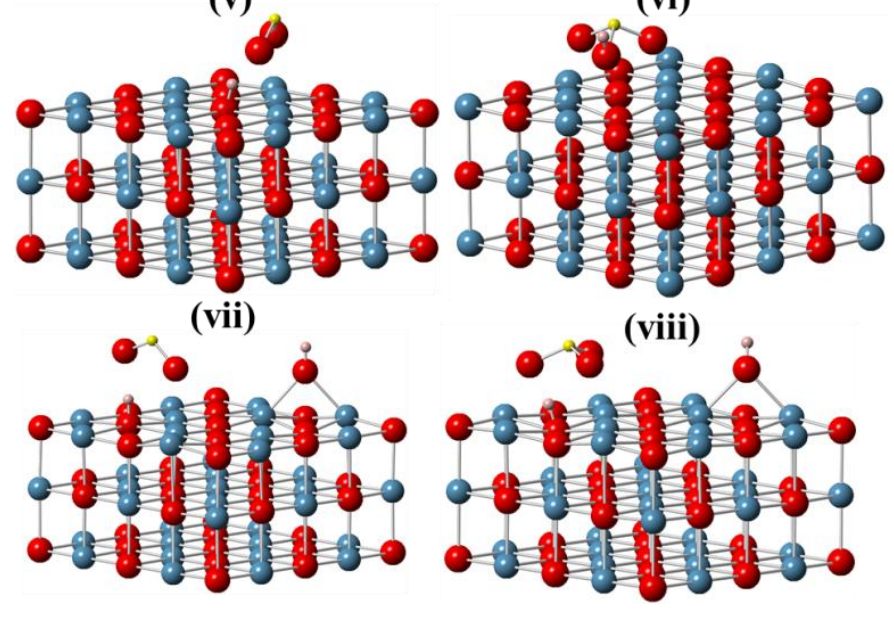

Figure 4. Surface configurations for bisulfite and bisulfate formation on $-\mathrm{OH}$ surfaces (i-ii) and $-\mathrm{H} \& \mathrm{OH}$ surfaces (iii-iv). Weak $\mathrm{H}+\mathrm{SO}_{\mathrm{x}}$ surface interactions between $\mathrm{SO}_{2}$ and $\mathrm{SO}_{3}$ on $-\mathrm{H}$ surfaces (v-vi) and - H\&OH surfaces (vii-viii). 


\begin{tabular}{|c|c|c|c|c|c|c|c|c|}
\hline \multirow[b]{2}{*}{\begin{tabular}{c|c|} 
Surface \\
Functional Group \\
\end{tabular}} & \multicolumn{2}{|c|}{ Bisulfite } & \multicolumn{2}{|c|}{ Bisulfate } & \multicolumn{2}{|c|}{$\mathrm{H}+\mathrm{SO}_{2}$} & \multicolumn{2}{|c|}{$\mathrm{H}+\mathrm{SO}_{3}$} \\
\hline & $-\mathrm{OH}$ & $-\mathbf{H} \& \mathbf{O H}$ & $-\mathrm{OH}$ & $-\mathrm{H} \& \mathrm{OH}$ & $-\mathbf{H}$ & $-\mathbf{H} \& \mathbf{O H}$ & $-\mathbf{H}$ & $-\mathrm{H} \& \mathrm{OI}$ \\
\hline $\begin{array}{c}\text { Binding Energy } \\
(\mathrm{kJ} / \mathrm{mol})\end{array}$ & 172 & 205 & 267 & 313 & 204 & 54 & 294 & 78 \\
\hline $\begin{array}{l}\text { S-Osox Bond } \\
\text { Distance }(\AA)\end{array}$ & 1.4893 & 1.494 & 1.4588 & 1.466 & 1.535 & 1.483 & 1.474 & 1.527 \\
\hline $\begin{array}{c}\text { S-O OH }(\text { or H) Bond } \\
\text { Distance (̊) } \\
\end{array}$ & 1.856 & 1.842 & 1.7139 & $\begin{array}{l}1.651 / \\
1.884 \\
\end{array}$ & 1.818 & 1.911 & 1.92 & 1.593 \\
\hline Bond Angle $\left({ }^{\circ}\right)$ & 111.704 & 2 & 114.969 & 1128 & 10 & 1146 & 113.7 & 108.6 \\
\hline $\begin{array}{c}\text { S-O } \text { Lat }_{\text {Lat }} \text { Distance } \\
(\AA \AA)\end{array}$ & 3.287 & 3.311 & 3.225 & 3.618 & 5.137 & 3.705 & 3.536 & 3.112 \\
\hline $\begin{array}{c}\begin{array}{c}\text { Shift in S-s orbital } \\
(\mathrm{eV})\end{array} \\
\end{array}$ & -1.15 & -1.56 & -1.02 & -1.48 & -1.8 & -2.70 & 0.11 & 0.51 \\
\hline $\begin{array}{c}\text { Shift in Other } \\
\text { Adsorbate-s } \\
\text { orbital }(\mathrm{eV}) \\
\end{array}$ & -4.72 & $\begin{array}{l}0.58 / \\
-5.52\end{array}$ & -6.23 & $\begin{array}{l}1.01 / \\
-7.08\end{array}$ & 0.26 & $\begin{array}{l}0.66 / \\
-0.27\end{array}$ & 1.5 & $\begin{array}{l}0.67 / \\
-0.32\end{array}$ \\
\hline $\begin{array}{c}\text { Total Charge } \\
\text { Transfer to } \mathrm{SO}_{\mathrm{x}}\end{array}$ & -0.249 & -0.083 & -1.06 & -0.062 & -0.998 & -0.434 & -1.57 & -1.355 \\
\hline
\end{tabular}

Table 4. Summary of results for weak surface interactions of $\mathrm{SO}_{2}$ and $\mathrm{SO}_{3}$ on the $-\mathrm{OH}$ and $-\mathrm{H}$ surfaces shown in Figure 4. 

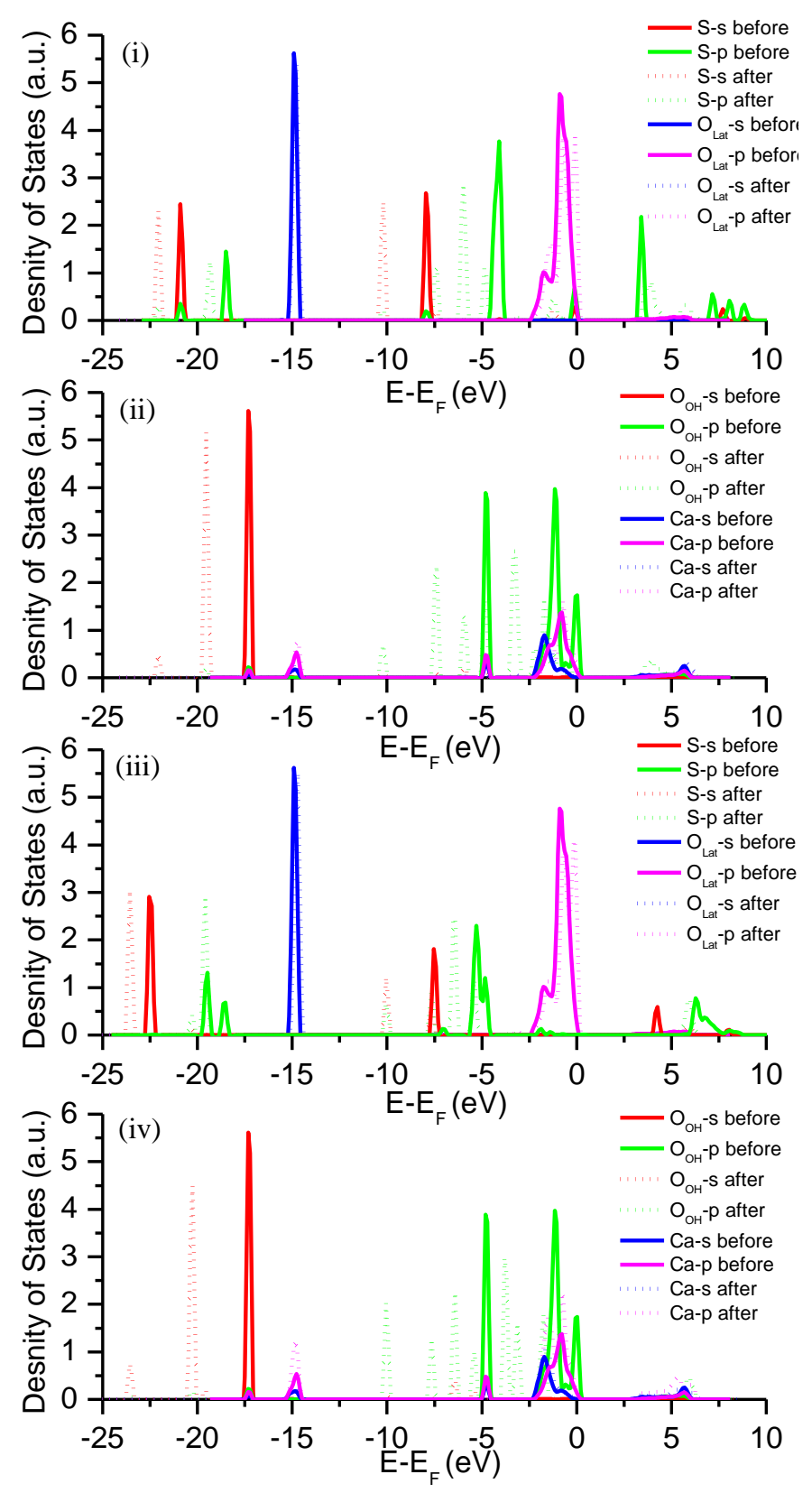

Figure 5. Density of state plots for bisulfite (i-ii) and bisulfate (iii-iv) formation on the $-\mathrm{OH}$ surface shown in Figure 4. 

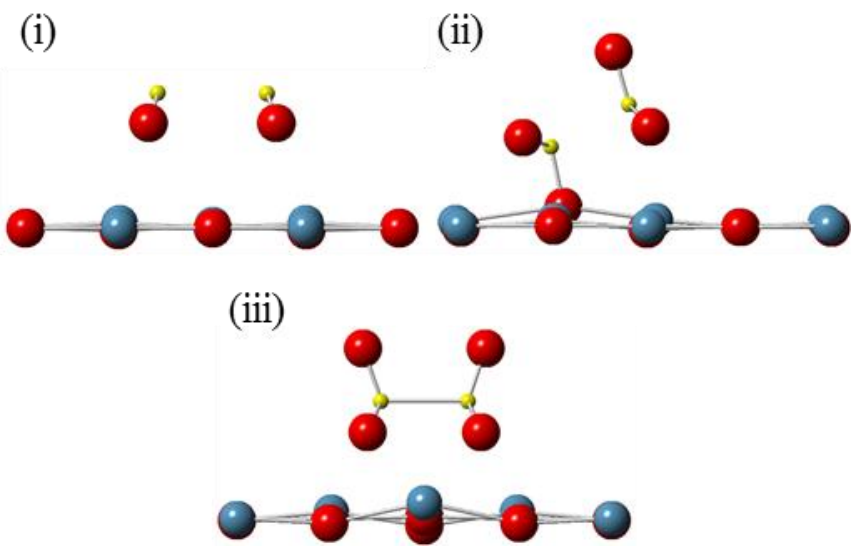

Figure 6. Final configuration for disulfur molecule formation from two $\mathrm{SO}_{\mathrm{x}}$ species in the gas phase resulting in (i) $\mathrm{S}_{2} \mathrm{O}_{4}$, (ii) $\mathrm{S}_{2} \mathrm{O}_{5}$, (iii) $\mathrm{S}_{2} \mathrm{O}_{6}$ 


\begin{tabular}{|c|c|c|c|c|c|c|}
\hline & $\mathbf{S}_{2} \mathbf{O}_{4}$ & $\begin{array}{c}\mathrm{S}_{2} \mathrm{O}_{4}{ }^{\mathrm{a}} \text {-Prev. } \\
\text { Lit. }\end{array}$ & $\mathbf{S}_{2} \mathbf{O}_{5}$ & $\begin{array}{c}\mathbf{S}_{2} \mathbf{O}_{5}{ }^{b}-\text { Prev. } \\
\text { Lit. }\end{array}$ & $\mathbf{S}_{2} \mathbf{O}_{6}$ & $\begin{array}{c}\mathrm{S}_{2} \mathrm{O}_{6}{ }^{\mathrm{c}}-\text { Prev. } \\
\text { Lit. }\end{array}$ \\
\hline $\begin{array}{c}\text { Binding Energy } \\
(\mathrm{kJ} / \mathrm{mol})\end{array}$ & 46 & N/A & 246 & N/A & 140 & N/A \\
\hline $\begin{array}{c}\text { S-S Bond } \\
\text { Distance (̊) }\end{array}$ & 2.830 & $2.35-2.40$ & 2.391 & 2.217 & 2.241 & 2.308 \\
\hline $\begin{array}{c}\text { S1-O Bond }_{1}-\text { Bo }(\AA) \\
\text { Distance }\end{array}$ & 1.477 & $1.50-1.52$ & 1.497 & 1.495 & 1.476 & 1.500 \\
\hline $\begin{array}{c}\mathrm{S}_{2}-\mathrm{O} \text { Bond } \\
\text { Distance }(\AA)\end{array}$ & 1.477 & $1.50-1.52$ & 1.472 & 1.463 & 1.476 & 1.500 \\
\hline $\begin{array}{c}\mathrm{S}_{2}-\mathrm{S}_{1}-\mathrm{O}_{1} \text { Bond } \\
\text { Angle }\left(^{\circ}\right)\end{array}$ & 113.6 & $\sim 110$ & 110.7 & 109.7 & 113.3 & 105.8 \\
\hline $\begin{array}{c}\mathbf{S}_{1}-\mathbf{S}_{2}-\mathbf{O}_{2} \text { Bond } \\
\text { Angle }\left(^{\circ}\right)\end{array}$ & 113.6 & $\sim 110$ & 114.4 & 112.4 & 113.3 & 105.8 \\
\hline $\begin{array}{l}\text { Shift in S-s } \\
\text { orbital }(e V)\end{array}$ & -2.13 & N/A & $-2.60 /-1.53$ & N/A & -0.30 & N/A \\
\hline $\begin{array}{c}\text { Total Charge } \\
\text { Transfer to } \mathrm{SO}_{\mathrm{x}}\end{array}$ & -0.814 & N/A & 0.032 & N/A & -2.019 & N/A \\
\hline
\end{tabular}

Table 5. Summary of results for disulfur molecule formation from two $\mathrm{SO}_{\mathrm{x}}$ species in gas phase as shown in Figure 6. The values calculated here are compared to those previously reported from experimental and computational studies.

${ }^{a}$ Reference [47, 49]

${ }^{\mathrm{b}}$ Reference [48]

${ }^{\mathrm{c}}$ Reference [47] 


\begin{tabular}{|c|c|c|c|c|}
\hline & $\mathbf{H}_{2} \mathbf{O}(\mathbf{v o l} \%)$ & $\mathbf{C O}_{2}(\mathbf{v o l} \%)$ & $\mathbf{S O}_{2}(\mathbf{p p m})$ & $\mathbf{S O}_{3}(\mathbf{p p m})$ \\
\hline $\begin{array}{c}\text { Air- } \\
\text { Combustion }\end{array}$ & 15 & 7 & 475 & 25 \\
\hline $\begin{array}{c}\text { Oxy- } \\
\text { Combustion }\end{array}$ & 25 & 70 & 2375 & 125 \\
\hline
\end{tabular}

Table 6. Gas compositions used for thermodynamic calculations. 


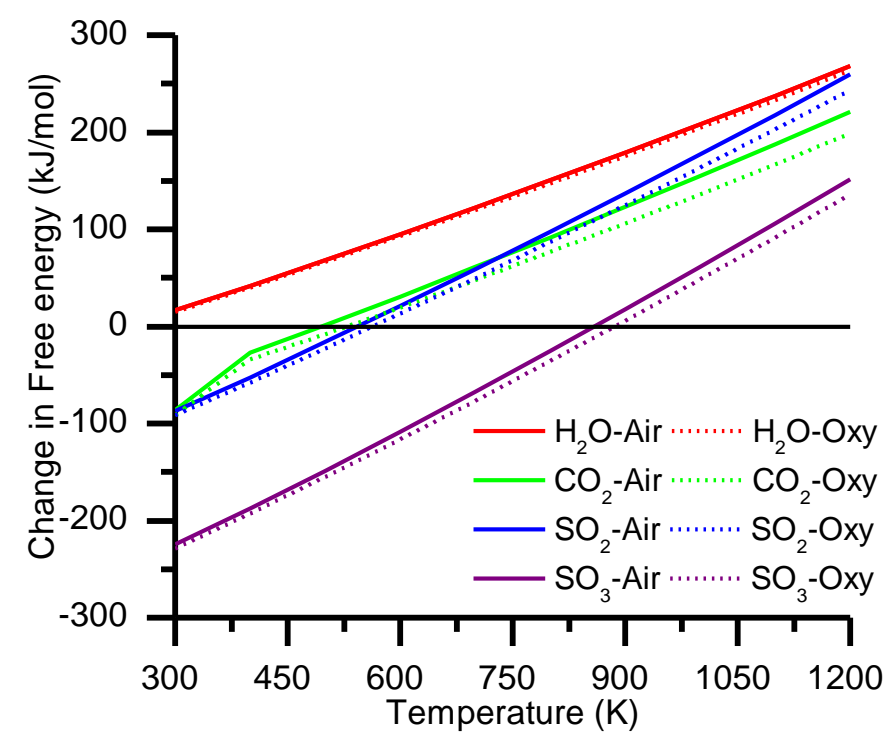

Figure 7. Results of ab-initio thermodynamic calculations for single adsorbates on $\mathrm{CaO}$ (100) surface under air- and oxy-combustion environments. 


\section{Bibliography}

[1] U.S. Energy Information Admistration. 2016. Electric Power Monthly. Retrieved August 23, 2016 from http://www.eia.gov/electricity/monthly/epm_table_grapher.cfm?t=epmt_1_1.

[2] C.-L. Chou, Sulfur in coals: A review of geochemistry and origins, Int. J. Coal Geol., 100 (2012) 1-13.

[3] U.S. Energy Information Admistration. 2013. Power plant emissions of sulfur dioxide and nitrogen oxides continue to decline in 2012. Retrieved August 25, 2016 from http://www.eia.gov/todayinenergy/detail.cfm?id=10151.

[4] Y. Mathieu, L. Tzanis, M. Soulard, J. Patarin, M. Vierling, M. Molière, Adsorption of SOx by oxide materials: A review, Fuel Process. Technol., 114 (2013) 81-100.

[5] K.T. Stanton, M.R. Towler, P. Mooney, R.G. Hill, X. Querol, Thermal analysis of fly ashes sourced from European non-blended coals, J. Chem. Technol. Biot., 77 (2002) 246-250.

[6] J.C. Hower, J.D. Robertson, G.A. Thomas, A.S. Wong, W.H. Schram, U.M. Graham, R.F. Rathbone, T.L. Robl, Characterization of fly ash from Kentucky power plants, Fuel, 75 (1996) 403-411.

[7] M. Ahmaruzzaman, A review on the utilization of fly ash, Prog. Energ. Combust., 36 (2010) 327-363.

[8] C.K. Stimpson, S. Chamberlain, D.R. Tree, Pulverized-Coal Deposits Collected Under Staged and Unstaged Oxy-Fuel Conditions for Four U.S. Coals, Combust. Sci. Technol., 185 (2013) 1098-1117.

[9] D. Yu, W.J. Morris, R. Erickson, J.O.L. Wendt, A. Fry, C.L. Senior, Ash and deposit formation from oxy-coal combustion in a $100 \mathrm{~kW}$ test furnace, Int. J. Greenh. Gas Con., 5, Supplement 1 (2011) S159-S167.

[10] D.W. Sturgeon, E.D. Cameron, F.D. Fitzgerald, Demonstration of an oxyfuel combustion system, Energy Procedia, 1 (2009) 471-478.

[11] J. Cheng, J. Zhou, J. Liu, Z. Zhou, Z. Huang, X. Cao, X. Zhao, K. Cen, Sulfur removal at high temperature during coal combustion in furnaces: a review, Prog. Energ. Combust., 29 (2003) 381-405.

[12] W.T. Davis, M.A. Fiedler, The Retention of Sulfur in Fly Ash from Coal-Fired Boilers, JAPCA J. Air. Waste Ma., 32 (1982) 395-397.

[13] C. Sheng, M. Xu, J. Zhang, Y. Xu, Comparison of sulphur retention by coal ash in different types of combustors, Fuel Process. Technol., 64 (2000) 1-11.

[14] R. Spörl, J. Maier, G. Scheffknecht, Sulphur Oxide Emissions from Dust-fired Oxy-fuel Combustion of Coal, Energy Procedia, 37 (2013) 1435-1447.

[15] E. Raask, Sulfate capture in ash and boiler deposits in relation to $\mathrm{SO}_{2}$ emission, Prog. Energ. Combust., 8 (1982) 261-276.

[16] L.P. Belo, R. Sporl, K.V. Shah, L.K. Elliott, R.J. Stanger, J. Maier, T.F. Wall, Sulfur Capture by Fly Ash in Air and Oxy-fuel Pulverized Fuel Combustion, Energy Fuels, 28 (2014) 5472-5479.

[17] P. Taerakul, P. Sun, D.W. Golightly, H.W. Walker, L.K. Weavers, B. Zand, T. Butalia, T.J. Thomas, H. Gupta, L.-S. Fan, Characterization and re-use potential of by-products generated from the Ohio State Carbonation and Ash Reactivation (OSCAR) process, Fuel, 86 (2007) 541553.

[18] B.W. Hall, C. Singer, W. Jozewicz, C.B. Sedman, M.A. Maxwell, Current status of the ADVOCATE process for flue-gas desulfurization, Journal of the Air \& Waste Management Association, 42 (1992) 103-110. 
[19] D. Fleig, K. Andersson, F. Normann, F. Johnsson, SO3 Formation under Oxyfuel Combustion Conditions, Ind. Eng. Chem. Res., 50 (2011) 8505-8514.

[20] D. Fleig, M.U. Alzueta, F. Normann, M. Abián, K. Andersson, F. Johnsson, Measurement and modeling of sulfur trioxide formation in a flow reactor under post-flame conditions, Combustion and Flame, 160 (2013) 1142-1151.

[21] M.C. Romano, I. Martínez, R. Murillo, B. Arstad, R. Blom, D.C. Ozcan, H. Ahn, S. Brandani, Process simulation of Ca-looping processes: review and guidelines, Energy Procedia, 37 (2013) 142-150.

[22] I. Martínez, G. Grasa, J. Parkkinen, T. Tynjälä, T. Hyppänen, R. Murillo, M.C. Romano, Review and research needs of Ca-Looping systems modelling for post-combustion $\mathrm{CO} 2$ capture applications, Int. J. Greenh. Gas Con., 50 (2016) 271-304.

[23] B.D. Galloway, R.A. MacDonald, B. Padak, Characterization of sulfur products on $\mathrm{CaO}$ at high temperatures for air and oxy-combustion, Int. J. Coal Geol., 167 (2016) 1-9.

[24] G. Kresse, J. Furthmüller, Efficiency of ab-initio total energy calculations for metals and semiconductors using a plane-wave basis set, Comput. Mat. Sci., 6 (1996) 15.

[25] G. Kresse, J. Furthmüller, Efficient iterative schemes for ab initio total-energy calculations using a plane-wave basis set, Phys. Rev. B, 54 (1996) 11169.

[26] G. Kresse, J. Hafner, Ab initio molecular dynamics for liquid metals, Phys. Rev. B, 47

(1993) 558.

[27] G. Kresse, J. Hafner, Ab initio molecular-dynamics simulation of the liquid-metal-

amorphous-semiconductor transition in germanium, Phys. Rev. B, 49 (1994) 14251.

[28] G. Kresse, J. Hafner, Norm-Conserving and Ultrasoft Pseudopotentials for First-Row and Transition-Elements, J. Phys.: Condens. Matter, 6 (1994) 8245.

[29] B.D. Galloway, E. Sasmaz, B. Padak, Binding of $\mathrm{SO}_{3}$ to fly ash components: $\mathrm{CaO}, \mathrm{MgO}$, $\mathrm{Na}_{2} \mathrm{O}$ and $\mathrm{K}_{2} \mathrm{O}$, Fuel, 145 (2015) 79-83.

[30] G. Kresse, D. Joubert, From ultrasoft pseudopotentials to the projector augmented-wave method, Phys. Rev. B, 59 (1999) 1758.

[31] P.E. Blöchl, Projector augmented-wave method, Phys. Rev. B, 50 (1994) 17953.

[32] J.P. Perdew, J.A. Chevary, S.H. Vosko, K.A. Jackson, M.R. Pederson, D.J. Singh, C.

Fiolhais, Atoms, Molecules, Solids, and Surfaces: Applications of the Generalized Gradient

Approximation for Exchange and Correlation, Phys. Rev. B, 46 (1992) 6671.

[33] J.P. Perdew, J.A. Chevary, S.H. Vosko, K.A. Jackson, M.R. Pederson, D.J. Singh, C.

Fiolhais, Erratum: Atoms, Molecules, Solids, and Surfaces: Applications of the Generalized

Gradient Approximation for Exchange and Correlation, Phys. Rev. B, 48 (1993) 4978.

[34] G. Henkelman, A. Arnaldsson, H. Jónsson, A fast and robust algorithm for Bader

decomposition of charge density, Computational Materials Science, 36 (2006) 354-360.

[35] E. Sanville, S.D. Kenny, R. Smith, G. Henkelman, Improved grid-based algorithm for Bader charge allocation, Journal of Computational Chemistry, 28 (2007) 899-908.

[36] W. Tang, E. Sanville, G. Henkelman, A grid-based Bader analysis algorithm without lattice bias, Journal of Physics: Condensed Matter, 21 (2009) 084204.

[37] M. Yu, D.R. Trinkle, Accurate and efficient algorithm for Bader charge integration, J.

Chem. Phys., 134 (2011) 064111.

[38] E.J. Karlsen, M.A. Nygren, L.G.M. Pettersson, Comparative Study on Structures and Energetics of NOx, SOx, and COx Adsorption on Alkaline-Earth-Metal Oxides, J. Phys. Chem. B, 107 (2003) 7795-7802. 
[39] E. Sasmaz, J. Wilcox, Mercury Species and SO2 Adsorption on CaO(100), J. Phys. Chem. C, 112 (2008) 16484-16490.

[40] N.H. de Leeuw, J.A. Purton, S.C. Parker, G.W. Watson, G. Kresse, Density functional theory calculations of adsorption of water at calcium oxide and calcium fluoride surfaces, Surf. Sci., 452 (2000) 9-19.

[41] N.H. de Leeuw, G.W. Watson, S.C. Parker, Atomistic Simulation of the Effect of Dissociative Adsorption of Water on the Surface Structure and Stability of Calcium and Magnesium Oxide, The Journal of Physical Chemistry, 99 (1995) 17219-17225.

[42] N. H. de Leeuw, S. C. Parker, Atomistic simulation of the effect of molecular adsorption of water on the surface structure and energies of calcite surfaces, Journal of the Chemical Society, Faraday Transactions, 93 (1997) 467-475.

[43] J. Carrasco, F. Illas, N. Lopez, Dynamic Ion Pairs in the Adsorption of Isolated Water Molecules on Alkaline-Earth Oxide (001) Surfaces, Physical Review Letters, 100 (2008) 016101.

[44] V. Vchirawongkwin, C. Kritayakornupong, B.M. Rode, Structural and Dynamical Properties and Vibrational Spectra of Bisulfate Ion in Water: A Study by Ab Initio Quantum Mechanical Charge Field Molecular Dynamics, J. Phys. Chem. B, 114 (2010) 11561-11569. [45] T.M. Townsend, A. Allanic, C. Noonan, J.R. Sodeau, Characterization of Sulfurous Acid, Sulfite, and Bisulfite Aerosol Systems, J. Phys. Chem. A, 116 (2012) 4035-4046.

[46] M.A. Martin, J.W. Childers, R.A. Palmer, Fourier Transform Infrared Photoacoustic Spectroscopy Characterization of Sulfur-Oxygen Species Resulting from the Reaction of $\mathrm{SO}_{2}$ with $\mathrm{CaO}$ and $\mathrm{CaCO}_{3}$, Appl. Spectrosc., 41 (1987) 120-126.

[47] M.L. McKee, Computational Study of the Mono- and Dianions of SO2, SO3, SO4, S2O3, S2O4, S2O6, and S2O8, The Journal of Physical Chemistry, 100 (1996) 3473-3481.

[48] K.L. Carter, T.A. Siddiquee, K.L. Murphy, D.W. Bennett, The surprisingly elusive crystal structure of sodium metabisulfite, Acta Crystallographica Section B-Structural Science, 60 (2004) 155-162.

[49] A. Magnusson, L.G. Johansson, The Crystal-Structure of Tin(II) Dithionite, $\mathrm{Sn}_{2}\left(\mathrm{~S}_{2} \mathrm{O}_{4}\right)_{2}$, Acta Chemica Scandinavica Series a-Physical and Inorganic Chemistry, 36 (1982) 429-433. [50] K. Reuter, M. Scheffler, Composition, structure, and stability of $\mathrm{RuO}_{2}(110)$ as a function of oxygen pressure, Physical Review B, 65 (2001) 035406.

[51] J. Rogal, K. Reuter, Ab-initio AtomisticThermodynamics for Surfaces: A Primer, in: Experiment, Modeling and Simulation of Gas-Surface Interactions for Reactive Flows in Hypersonic Flights. Educational Notes RTO-EN-AVT-142, p. 2-1-2-18, Neuilly-sur-Seine 2007.

[52] S.C. Ammal, A. Heyden, Water-Gas Shift Catalysis at Corner Atoms of Pt Clusters in Contact with a TiO2 (110) Support Surface, ACS Catalysis, 4 (2014) 3654-3662.

[53] J. Lu, S. Behtash, M. Faheem, A. Heyden, Microkinetic modeling of the decarboxylation and decarbonylation of propanoic acid over $\operatorname{Pd}\left(\begin{array}{lll}1 & 1 & 1\end{array}\right)$ model surfaces based on parameters obtained from first principles, J. Catal., 305 (2013) 56-66.

[54] M. Chase, NIST-JANAF Thermochemical Tables, American Chemical Society, Woodbury, NY, 1998.

[55] D.A. Cleary, Use of JANAF Tables in Equilibrium Calculations and Partition Function Calculations for an Undergraduate Physical Chemistry Course, Journal of Chemical Education, $91(2014)$ 848-852. 
[56] J. Baltrusaitis, C.R. Usher, V.H. Grassian, Reactions of sulfur dioxide on calcium carbonate single crystal and particle surfaces at the adsorbed water carbonate interface, Physical Chemistry Chemical Physics, 9 (2007) 3011-3024.

[57] H.A. Al-Hosney, V.H. Grassian, Water, sulfur dioxide and nitric acid adsorption on calcium carbonate: A transmission and ATR-FTIR study, Physical Chemistry Chemical Physics, 7 (2005) 1266-1276.

[58] L. Duan, Z. Jiang, X. Chen, C. Zhao, Investigation on water vapor effect on direct sulfation during wet-recycle oxy-coal combustion, Applied Energy, 108 (2013) 121-127.

[59] Z. Jiang, L. Duan, X. Chen, C. Zhao, Effect of Water Vapor on Indirect Sulfation during Oxy-fuel Combustion, Energy Fuels, 27 (2013) 1506-1512.

[60] L.F. de Diego, A. Rufas, F. García-Labiano, M. de las Obras-Loscertales, A. Abad, P. Gayán, J. Adánez, Optimum temperature for sulphur retention in fluidised beds working under oxy-fuel combustion conditions, Fuel, 114 (2013) 106-113.

[61] F. García-Labiano, A. Rufas, L.F. de Diego, M.d.1. Obras-Loscertales, P. Gayán, A. Abad, J. Adánez, Calcium-based sorbents behaviour during sulphation at oxy-fuel fluidised bed combustion conditions, Fuel, 90 (2011) 3100-3108.

[62] W.T. Reid, Basic factors in capture or sulfur dioxide by limestone and dolomite, Journal of Engineering for Power, 92 (1970) 11-\&.

[63] C. Wang, L. Jia, Y. Tan, E.J. Anthony, Carbonation of fly ash in oxy-fuel CFB combustion, Fuel, 87 (2008) 1108-1114.

[64] Z.-H. Li, Y. Wang, K. Xu, J.-Z. Yang, S.-B. Niu, H. Yao, Effect of steam on CaO regeneration, carbonation and hydration reactions for $\mathrm{CO} 2$ capture, Fuel Process. Technol., 151 (2016) 101-106.

[65] M.J.D. Low, A.J. Goodsel, N. Takezawa, Reactions of gaseous pollutants with solids. I. Infrared study of the sorption of sulfur dioxide on calcium oxide, Environmental Science \& Technology, 5 (1971) 1191-1195.

[66] E. Zintl, A. Harder, B. Dauth, The atomic structure of the oxides, sulphides, selenides and tellurides of lithium, sodium and kalium, Z. Elektrochem. Angew. Phys. Chem., 40 (1934) 588593.

[67] CRC: Handbook of Chemistry and Physics, 84th Edition, CRC Press, Boca Raton, 2004. 